Research Article

\title{
Subsidence Prediction of Overburden Strata and Surface Based on the Voussoir Beam Structure Theory
}

\author{
Changchun $\mathrm{He}^{1,2}$ and Jialin $\mathrm{Xu}$ (D) $^{1,2}$ \\ ${ }^{1}$ School of Mines, China University of Mining and Technology, Xuzhou, Jiangsu 221116, China \\ ${ }^{2}$ State Key Laboratory of Coal Resources and Safe Mining, Xuzhou, Jiangsu 221116, China \\ Correspondence should be addressed to Jialin Xu; cumtxjl@cumt.edu.cn
}

Received 14 February 2018; Accepted 21 March 2018; Published 31 May 2018

Academic Editor: Dengke Wang

Copyright (c) 2018 Changchun $\mathrm{He}$ and Jialin $\mathrm{Xu}$. This is an open access article distributed under the Creative Commons Attribution License, which permits unrestricted use, distribution, and reproduction in any medium, provided the original work is properly cited.

\begin{abstract}
The hard and stiff strata (key strata) bear the overburden load in the form of a voussoir beam structure (VBS) after break. The VBS affects both the surface subsidence and the stope underground pressure. Therefore, the reasonable method to predict the surface subsidence is based on the whole subsidence formulae of the VBS. This study first establishes the subsidence formulae of the VBS analytically. The influence of the block length on the subsidence curve and the VBS level on the zero-subsidence range are then analyzed based on the subsidence formulae of the VBS. The results show the half-subsidence curve of the VBS is an S-shaped curve. The block length hardly affects the S-shaped subsidence curve determined by the width of the undercompacted zone. Furthermore, a greater undercompacted zone width corresponds to a greater offset distance of the inflection point. The higher the VBS level, the farther the zero-subsidence range, and the flatter the subsidence curve. The subsidence of the highest VBS can approximately represent the surface subsidence when the topsoil is thin enough.
\end{abstract}

\section{Introduction}

Coal mining will lead to overburden fracturing [1, 2], groundwater pollution [3-6], and landslides [7]. Moreover, all of the environmental damage relates to the surface subsidence. Therefore, it is especially important to study the surface subsidence caused by coal mining. To date, several methods can be used to predict the surface subsidence, including profile function [8], modelling [9], and influence function [10-12] methods. Most of these approaches are in light of ground station-based statistics predicting the surface subsidence without considering the control action of the key strata (KS) on the surface subsidence. However, field observations and physical model simulations have shown that the KS dynamically controls the surface subsidence [13-15], which means that the KS and the controlled soft rocks obtain synchronous subsidence and subsidence speed. This suggests that in order to accurately predict the surface subsidence, it is necessary to first calculate the KS subsidence within the overburden.
The overlying strata are usually divided into a caved zone, a fractured zone, and a continuous deformation zone [16]. The KS in different zones will present different characteristics. The KS in a caved zone will collapse after mining while that in a fractured zone will bear the overlying load with the voussoir beam structure (VBS). Meanwhile, the KS in a continuous deformation zone deform like a complete rock beam. The KS controls the surface subsidence in the form of a VBS when the coal seam is not deeply buried. Therefore, the subsidence formulae of the VBS should be determined before predicting the surface subsidence. The deformation mechanisms and the stability of undermined sedimentary rock layers have been studied $[17,18]$, but the influence of the VBS on the overlying strata subsidence was not considered. An enhanced subsurface subsidence prediction model considering overburden stratifications had been derived in the literature [19]. This model equally divides the overburden strata into a finite number of layers and considers the percent of hard rocks in each layer. The subsidence of each layer is then predicted progressively 


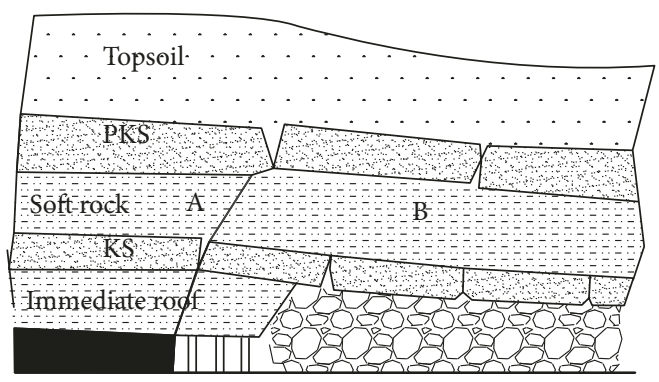

(a)

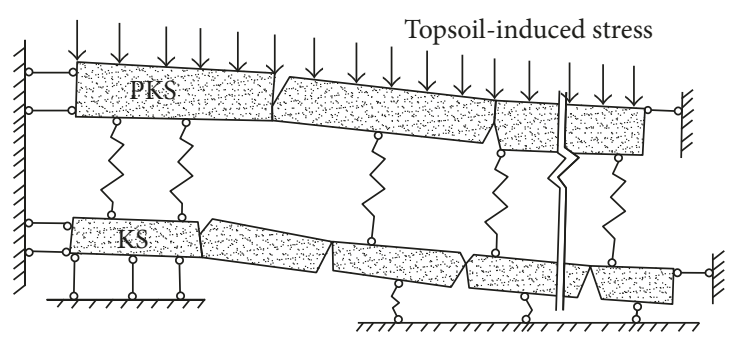

(b)

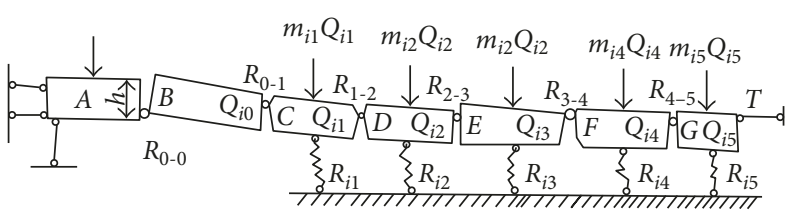

(c)

FIGURE 1: The mechanical model of the longwall overburden voussoir beam structure.

upward based on the influence function method. The model provides a new method for the subsurface subsidence prediction, but it does not consider the control action of the KS and only divides the overburden strata into several equal parts. The proposal of the "voussoir beam theory" [20] based on field measurements brought a qualitative leap to the understanding of the stope underground pressure. The mechanical model of the VBS proved that the KS after break was essentially a semiarch structure, despite it looking like a rock beam. The condition was that the key block in the VBS must meet the condition of "S-R" (sliding-rotation) stability. The voussoir beam theory explained the structure form of the overburden strata after coal seam mining, the reason for the front abutment pressure greater than the rear abutment pressure, and the displacement constraints above "immediate roof supports" [21]. The voussoir beam theory could explain most of the stope underground pressure phenomena and guides the control of the stope underground pressure and the prevention of roof accidents. Hence, the Mining and Metallurgy roll of the encyclopedia of China has accepted the "voussoir beam" concept. However, the mechanical model of the VBS only analyzes the force balance and displacement of the breaking blocks and does not provide the whole subsidence formulae, which are the basis for the calculation of overburden strata subsidence and the surface subsidence.

The analytical formulae of the whole VBS subsidence are initially derived and used to analyze the influence of the VBS level on the zero-subsidence range and the block length on the subsidence curve. Field tests are then utilized to validate the analytical subsidence formulae. The VBS subsidence can approximately represent the surface subsidence when the topsoil is extremely thin, but it cannot represent the surface subsidence when the topsoil is thick because the topsoil has its own complex movement law. The effect of the topsoil, if it is thick enough, should not be ignored in predicting the surface subsidence based on the overburden strata subsidence. Moreover, the surface subsidence can be theoretically calculated according to the deformation characteristics of the topsoil and the relationship between the surface and the VBS. Herein, only the VBS subsidence is studied, which will be the basis for the overburden subsidence-based surface subsidence prediction.

\section{Subsidence Formula of the VBS above the Mined-Out Area}

The overlying voussoir beam is divided into two parts (i.e., one above the mined-out area and another above the rib side separated by the blue line and represented with capital $A$ and B, respectively, in Figure 1(a)). This is because the breaking blocks above the mined-out area interlock with each other, forming a stable mechanical structure and bearing the overburden load, while the voussoir beam above the rib side deforms in the form of an unbroken beam. Furthermore, different external forms of the voussoir beam have different mechanical models. One is the continuous mechanical model, and another is the discontinuous mechanical model.

Figure 1(c) presents the simplified force diagram involving seven blocks based on Figure 1(a). The stress on the VBS is assumed to be linear from the first block near the rib to the horizontal block because the first block and the horizontal block are on the separation zone and the compacted zone, respectively. Structural mechanics defines the degree of freedom of this VBS to be zero. Hence, this model is a statically determinate problem, and the subsidence of each block can be derived based on the structural relationship of static equilibrium.

Each block has the same length $L . R_{i}$ represents the support forces of each block. $Q_{i}$ denotes the resultant loads calculated with the block central stress multiplying the block length and acting on the block center because stress slightly changes on one block. $\Delta_{i}$ is the rock compression at the point of support forces. $d_{i}$ is the relative subsidence of two endpoints of one block, and $h$ is the block thickness. 
The measured width of the undercompacted zone in the Datun Kongzhuang colliery is approximately $60-80 \mathrm{~m}$, and the block length is $7-16 \mathrm{~m}$. Therefore, seven blocks are desirable in the
VBS. The Cartesian coordinate system is located at the coal rib. The block mechanical relationship can be expressed as follows according to the static equilibrium of the VBS:

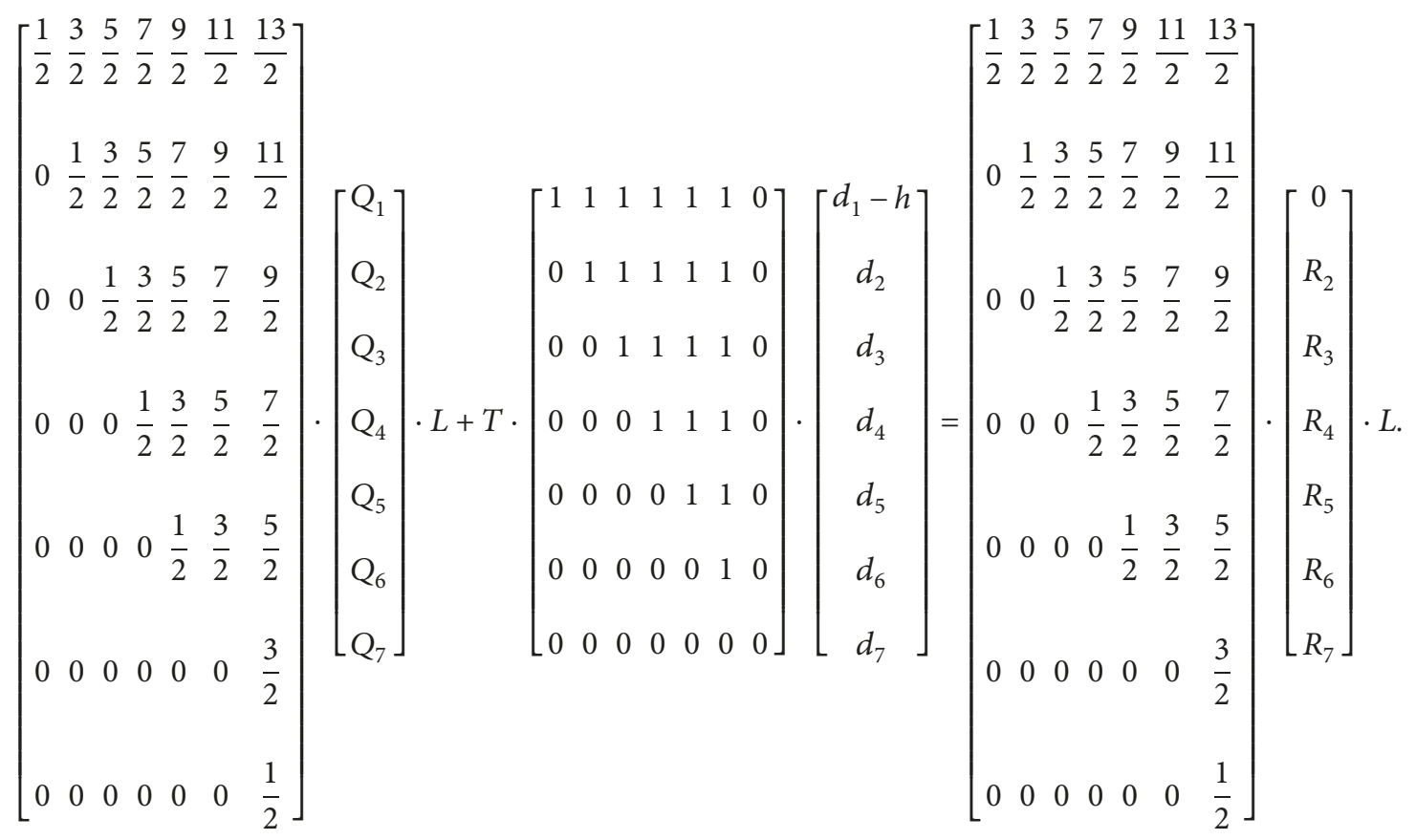

The rock mass under the voussoir beam comprises the whole caved zone rocks and the partial fractured zone rocks. Figure 2 shows the stress-strain curve of the caved zone rocks in the mined-out area based on Su et al. [22], and this stress-strain curve is similar to that listed in the literature [22]. Figure 3 presents the load-displacement curve based on the authors' measured rock core experiments. Figure 2 depicts that the three polynomial fitting degree of the stress-strain curve is very high. The load-displacement relationship of the caved zone rocks can satisfy (2) because the stress-strain relationship can be converted to a loaddisplacement relationship and the overall curve trend is kept unchanged. Figure 3 shows that the load-displacement relationship of the rock cores does not completely satisfy (2), and the correlation coefficient is only 0.73 . However, the compression mainly concentrates on the caved zone rocks. Furthermore, the load-displacement relationship of the fractured zone rocks can approximately satisfy (2). Therefore, the support forces can be assumed to be proportional to the cube of rock compressions:

$$
R_{i}=k \Delta_{i}^{3}
$$

where $k$ is the proportional coefficient, which can be back calculated with the maximum load and the maximum subsidence of the voussoir beam. The maximum load is the weight of the overlying rock strata [23], including the weight of the voussoir beam itself. The compression can be derived through the following equation because the subsidence of the voussoir beam equals the compression of the rock mass under the voussoir beam:

$$
\Delta=M-\sum h(b-1)
$$

where $M$ is the mining height, $\sum h$ is the thickness from the coal seam to the voussoir beam, and $b$ is the bulking coefficient.

The first block of the VBS is located in the bed separation zone. Hence, no interaction exists between the first block and the underlain soft rocks. Compression starts from the second block of the VBS. The compressions at the position of the support forces are presented as follows according to the geometric relationship of the interlocked blocks:

$$
\left[\begin{array}{l}
\Delta_{2} \\
\Delta_{3} \\
\Delta_{4} \\
\Delta_{5} \\
\Delta_{6} \\
\Delta_{7}
\end{array}\right]=\left[\begin{array}{cccccc}
1 & 0.5 & 0 & 0 & 0 & 0 \\
1 & 1 & 0.5 & 0 & 0 & 0 \\
1 & 1 & 1 & 0.5 & 0 & 0 \\
1 & 1 & 1 & 1 & 0.5 & 0 \\
1 & 1 & 1 & 1 & 1 & 0.5 \\
1 & 1 & 1 & 1 & 1 & 1
\end{array}\right] \cdot\left[\begin{array}{l}
d_{1} \\
d_{2} \\
d_{3} \\
d_{4} \\
d_{5} \\
d_{6}
\end{array}\right] .
$$

The compressions at the position of the support forces of each block can be calculated by combining (1-4). The subsidence of each block can then be obtained because the subsidence of each block is equal to the rock compression. Note that the subsidence of each block here is relative. Assignments are made to variables for an intuitive 
understanding of the VBS subsidence above the mined-out area. The overburden weight is $3 \mathrm{MPa}$, the block length is $L=15 \mathrm{~m}$, the block thickness is $h=5 \mathrm{~m}$, the mining height is $M=3 \mathrm{~m}$, and the thickness from the coal seam to the voussoir beam is $\sum h=30 \mathrm{~m}$. The bulking coefficient is $b=1.05$, and the maximum compression is 1.5 , which is calculated using (3). Therefore, the proportional coefficient is $k=13.33 \mathrm{MN} \cdot \mathrm{m}^{-3}$. The subsidence at each block center is obtained (Figure 4 ) by combining (1-4) with the assignments.
The abovementioned VBS only involves seven blocks, but the number of blocks is variant in different geological conditions because the number of blocks is determined by the width of the undercompacted zone and the block length. Equation (5) is provided herein to compute the subsidence of any number of interlocked blocks and facilitate the applications in different geological conditions. The geometrical relationships can also be derived in the same manner as in (4). The subsidence of each block is then calculated in line with the load-displacement relationship.

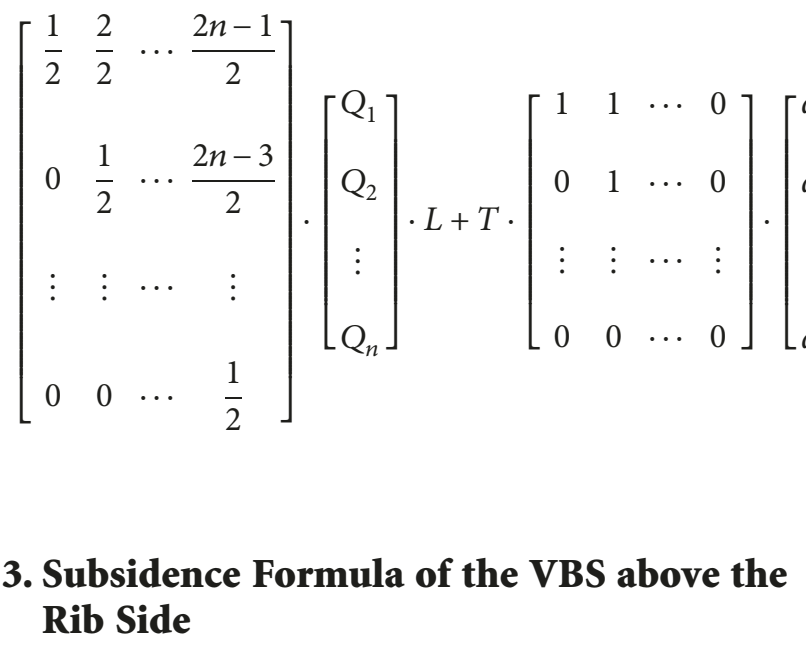

The voussoir beam above the rib side also subsides, except for the subsidence above the mined-out area. Zone $\mathrm{A}$ in Figure 1 is enlarged and shown in Figure 5. According to the limit angle in mining subsidence engineering, the higher the level, the farther the subsidence. In other words, the zerosubsidence point extends further as the VBS level becomes far away from the coal seam. The subsidence of the voussoir beam above the rib side is determined by lithology and stress magnitude. The soft rock mass leads in more compression and more VBS subsidence. The VBS subsidence above the rib side is nonnegligible unless the stress is small and the rock mass is hard. The deformation law of the voussoir beam above the rib side is similar to the elastic beam caused by the absence of failure. Therefore, the subsidence can be solved with material mechanics. The friction at the top and bottom surfaces of the voussoir beam is in the opposite direction. The friction coefficients and the stress on both surfaces are almost the same. Consequently, friction can be ignored. Moreover, ignoring the axial force, the differential equation of the voussoir beam becomes

$$
E I \frac{\mathrm{d}^{4} y}{\mathrm{~d} x^{4}}=q(x)-p(x),
$$

where $E$ is the elastic modulus, $I$ is the cross section moment of inertia, $p$ is the stress on the bottom surface of the voussoir beam, and $q$ is the stress on the top surface of the voussoir beam.

Figure 5(a) shows the real stress on the top surface of the voussoir beam and the state of the rock mass under the voussoir beam after the coal seam excavation. The partial rock mass under the voussoir beam is in a plastic state. Hence, there is no analytically effective method of obtaining the voussoir beam subsidence. Assuming the rock mass under the voussoir beam to be in an elastic state is the general approach to acquire the voussoir beam subsidence. That is, the voussoir beam deforms on an elastic foundation. As for the stress on the top surface of the voussoir beam, basically, all methods suppose that the stress distribution is Weibull or uniformly distributed. A uniformly distributed stress is unreasonable because a uniformly distributed stress simultaneously exists with strata sedimentation and does not cause any subsidence, which is caused by the additional stress transferred from the weight of the overlying strata above the mined-out area. The Weibull distributed stress results from the fact that the rock mass is overstressed and becomes plastic, and then, stress gradually transfers to a distant rock mass until a new equilibrium is obtained. The Weibull distributed stress is not reasonable because the foundation under the voussoir beam is assumed to be elastic, and Weibull distributed stress is the result of a plastic rock mass. Moreover, the Weibull distributed stress theoretically leads to a significantly small subsidence of the voussoir beam. In fact, if the rock mass of the rib side is forever elastic, the nearest point to the rib can bear all the weight of the rock strata above the mined-out area, and the additional weight will not transfer to a distant rock mass. Thus, the point load shown in Figure 5(b) should be the actual stress state for the elastic rock mass. Meanwhile, the stress on the bottom surface of the voussoir beam is proportional to the subsidence. Equation (6) then becomes 


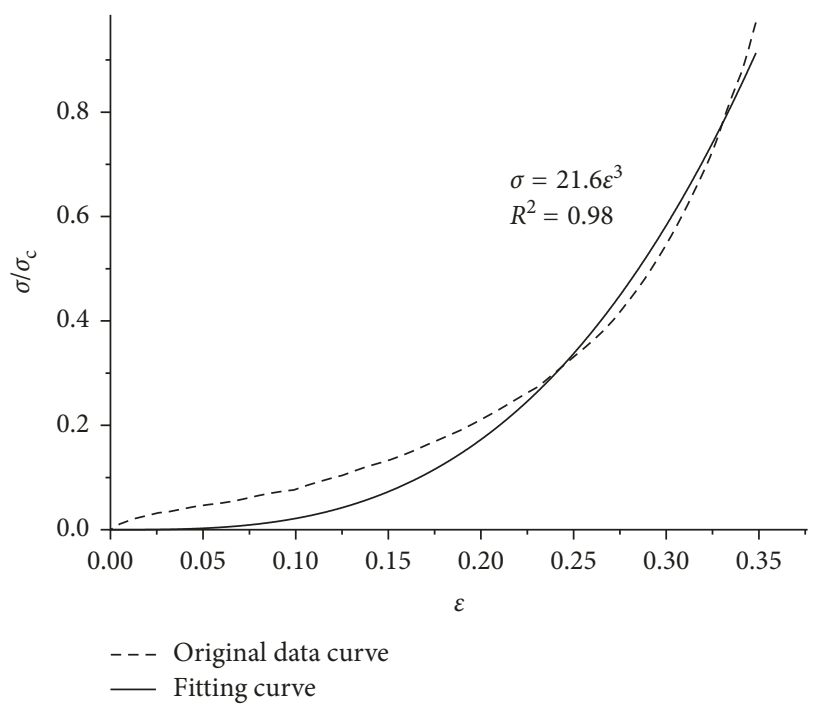

FIGURE 2: Stress-strain curve of the caved zone rock mass.

$$
E I \frac{\mathrm{d}^{4} y}{\mathrm{~d} x^{4}}+k_{1} y=q,
$$

where $k_{1}$ is the coefficient of elastic foundation, namely, the stress to displacement ratio. Many rock strata usually exist under the voussoir beam, including the coal seam. Suppose that there are $n$ layers of the rock beam, numbered $1, \ldots, n$ starting from the coal seam. The elastic modulus of each stratum is $E_{i}$, while the thickness is $h_{i}$. The coefficient of elastic foundation can then be presented as

$$
\frac{1}{k_{1}}=\frac{h_{1}}{E_{1}}+\frac{h_{2}}{E_{2}}+\cdots+\frac{h_{n}}{E_{n}} .
$$

Setting $\beta=\sqrt[4]{k_{1} / E I}$, the general solution of the fourthorder ordinary differential in (7) is obtained as

$$
\begin{aligned}
y= & e^{\beta x}(A \cos \beta x+B \sin \beta x) \\
& +e^{-\beta x}(C \cos \beta x+D \sin \beta x)+q / k_{1} .
\end{aligned}
$$

Four boundary conditions must be considered to determine the four coefficients (i.e., $A, B, C$, and $D$ ) of (9). The infinite point of the voussoir beam is a fixed boundary, indicating that the subsidence and the rotational angle here are zero. Only the shear force exists in the right boundary of the voussoir beam, and the shear force is equal to the weight of the rock mass above the first layer of the voussoir beam, including the weight of the voussoir beam itself. Consequently, the boundary conditions are summarized as follows:

$$
\begin{aligned}
\text { Left boundary } \quad y(-\infty) & =0, \quad y^{\prime}(-\infty)=0, \\
\text { Right boundary } \quad y^{\prime}(l) & =0, \quad y^{\prime \prime \prime}(l)=Q / E I,
\end{aligned}
$$

where $l$ is the horizontal distance from the origin to the right boundary, which can be calculated by the broken angle $\varphi$ and the distance from the coal seam to the voussoir beam $\sum h . Q$ is the shear force on the right boundary equal to the weight of the rock mass above the first layer of the voussoir beam, including the weight of the voussoir beam itself. $q$ is zero

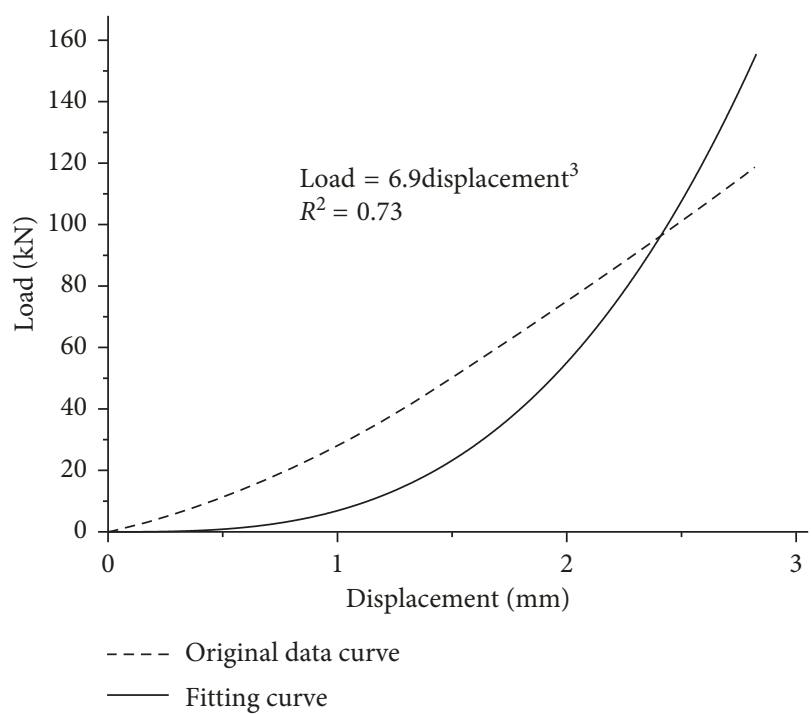

FIgURE 3: Load-displacement curve of rock cores.

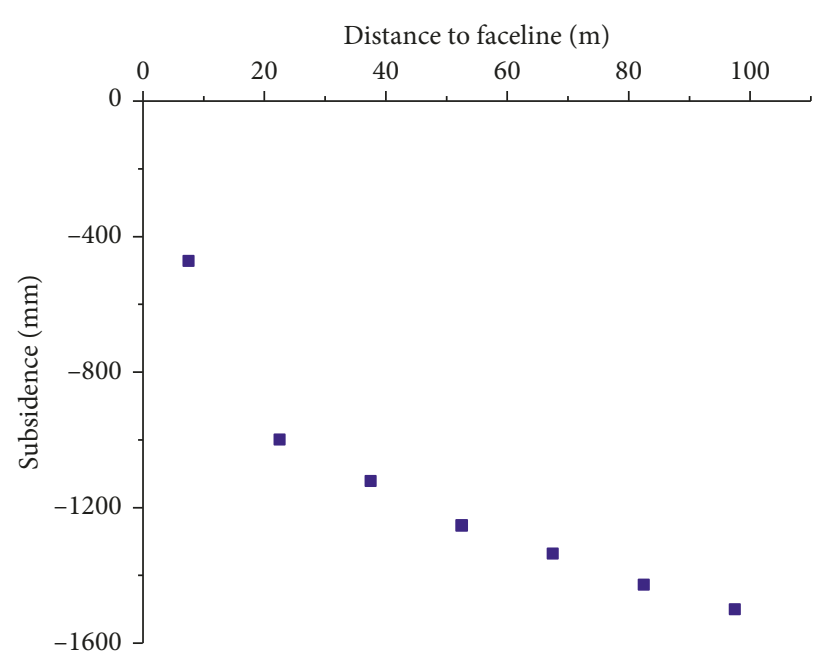

FIGURE 4: Relative subsidence of the voussoir beam structure above the mined-out area.

because the voussoir beam subsidence results from the additional load and not from the stress existing before the coal excavation, which would not cause any subsidence. The magnitude of the additional load is related to the breakage of the voussoir beam and the mining conditions. The weight of the rock mass above the mined-out area will all be borne by the rib side if the voussoir beam above the mined-out area does not break. In supercritical mining, the weight of the rock mass over the undercompacted zone half-transfers to the rib side, but no weight of the rock mass over the compacted zone shifts to the rib side. Let $S$ represent the width of the undercompacted zone and $\gamma$ be the average unit weight of the overburden rock mass. $Q$ is then equal to $S \gamma H / 2 . H$ is the buried depth of the voussoir beam.

Taking the boundary conditions into the first, second, and third derivatives of (9), the subsidence of the voussoir beam above the rib side becomes 


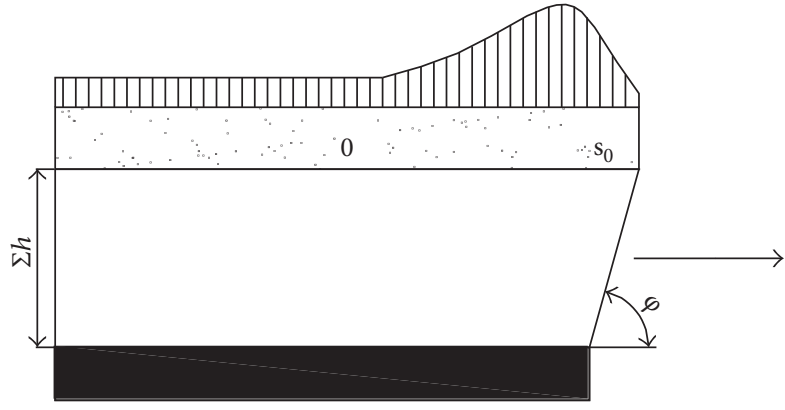

(a)

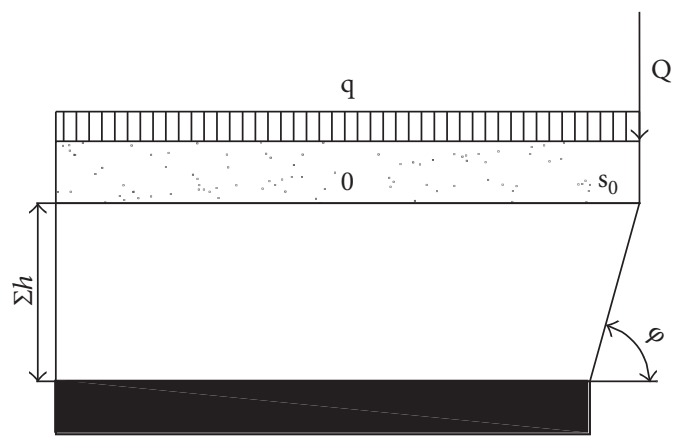

(b)

Figure 5: Mechanical state of the voussoir beam above the rib side. (a) Plastic foundation; (b) elastic foundation.

$$
y=-\frac{Q}{2 \beta^{3} e^{\beta l} E I} e^{\beta x} \cos \beta(l-x) .
$$

The mining height is $M=3 \mathrm{~m}$. The thickness from the coal seam to the voussoir beam is $\sum h=30 \mathrm{~m}$. The weight of the rock mass on the voussoir beam is $3 \mathrm{MPa}$, while the width of the undercompacted zone is $S=80 \mathrm{~m}$. The shear force is $Q=120 \mathrm{MN} / \mathrm{m}$. The elastic modulus of the rock mass from the coal seam to the voussoir beam is $7 \mathrm{GPa}$, while that of the coal seam is $5 \mathrm{GPa}$ and that of the voussoir beam is $E=30 \mathrm{GPa}$. The voussoir beam thickness is $h=5 \mathrm{~m}$. The breaking angle is $\varphi=70^{\circ}$ and $1=10.92 \mathrm{~m}$. Figure 6 shows the subsidence of the voussoir beam above the rib side after calculating (11) with assignments. Figure 6 depicts that the subsidence at the right boundary is the maximum. Furthermore, the voussoir beam uplifts in a distance from the right boundary. However, this phenomenon is not obvious.

\section{Half-Subsidence Curve of the VBS and Influence Factors}

4.1. Half-Subsidence Curve of the VBS. Combining the VBS subsidence above the mined-out area with that above the rib side results in the half-subsidence curve of the VBS. Its formulae are shown in (12). Taking the previous assignments as an example, Figure 7 shows the half-subsidence curve of the VBS. Figure 7 also illustrates that the half-subsidence curve is an S-shaped curve. Its shape is determined by the block length, block thickness, load, VBS level, and mining height. Note that the VBS subsidence above the mined-out area should add the maximum subsidence of the VBS above the rib side because the VBS subsidence above the mined-out area is relative to a fixed point. The VBS subsidence above the mined-out area obtains a corresponding subsidence when the fixed point subsides. In other words, the subsidence above the mined-out area is relative, whereas that above the rib side is absolute.

$$
\begin{aligned}
& y(x)=-\frac{Q}{2 \beta^{3} e^{\beta l} E I} e^{\beta x} \cos \beta(l-x) \\
& y_{i}=y(l)-\left[\begin{array}{cccc}
0.5 & 0 & \cdots & 0 \\
1 & 0.5 & \cdots & 0 \\
\vdots & \vdots & \cdots & \vdots \\
1 & 1 & \cdots & 1
\end{array}\right] \cdot\left[\begin{array}{c}
d_{1} \\
d_{2} \\
\vdots \\
d_{n}
\end{array}\right]\left(d_{1}, \ldots, d_{n} \text { computed according to }(5)\right) \quad x \geq l .
\end{aligned}
$$

\subsection{Influence Factors on the VBS Subsidence}

4.2.1. Influence of the Block Length and the Width of the Undercompacted Zone on the VBS Subsidence. The block length is decided by stress on the VBS and its hardness. Small stress has a longer block length, while great hardness provides a short block length. Figure 8 illustrates the influence of the block length on the VBS subsidence. The assignments are the same with those used in Figures 4 and 6, except for the block length. Figure 9 shows that the S-shaped subsidence curve of different block lengths is almost the same. It can then be concluded that the block length hardly affects the subsidence curve shape. Therefore, a roughly reasonable block length is suitable for the subsidence calculation. Each block length of the overburden VBS is difficult to determine. Hence, the above conclusion makes the prediction of the overburden subsidence simple and feasible. Figure 9 presents the influence of the width of the undercompacted zone on the VBS subsidence, where the width is shown to affect the subsidence curve shape. The elliptical zone represents the 


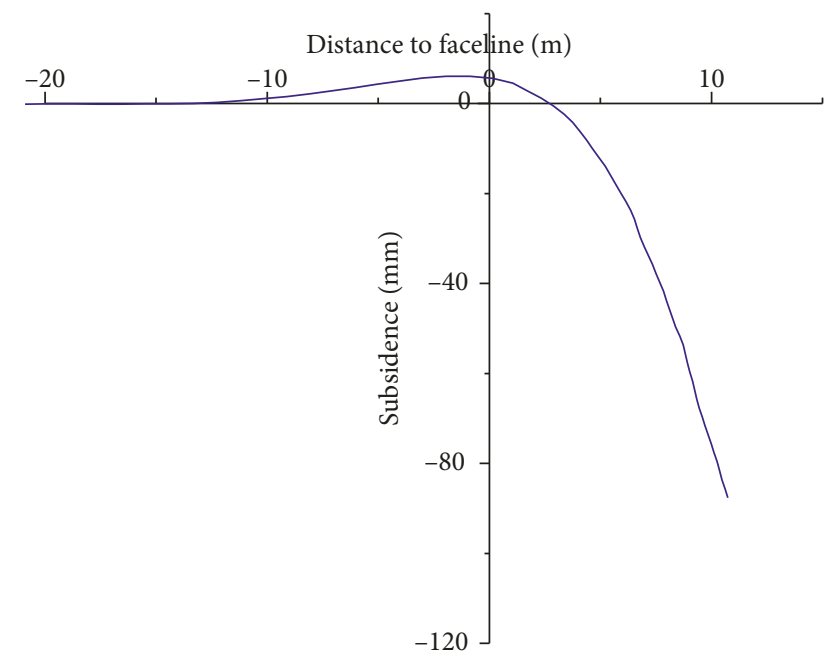

FIGURE 6: Subsidence of the voussoir beam structure above the rib side.

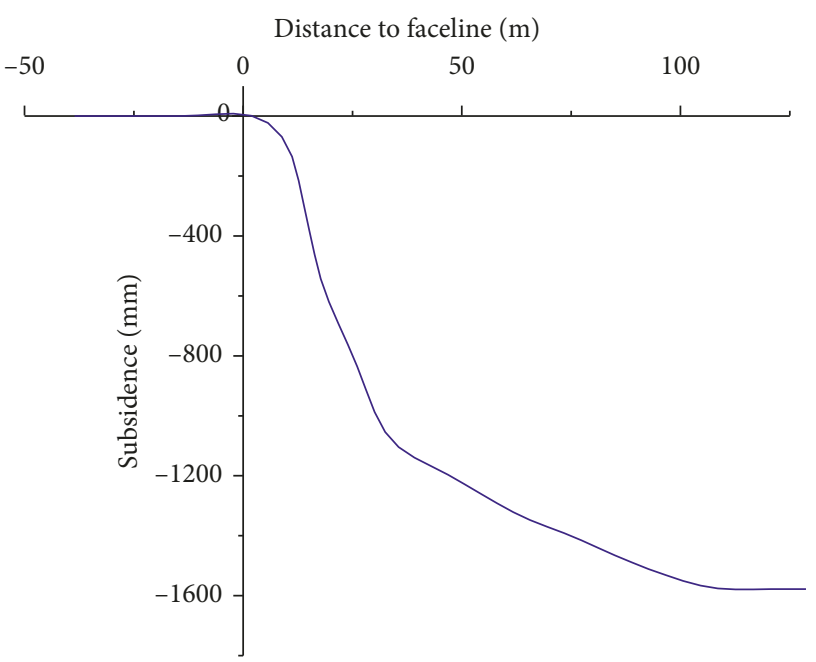

Figure 7: Half-subsidence curve of the voussoir beam structure.

offset distance of the inflection point. Therefore, the higher undercompacted zone width corresponds a higher offset distance of the inflection point.

4.2.2. Influence of the Level on the VBS Subsidence. Different levels normally involve a variation of other factors, such as load, elastic modulus, and bulking coefficient. The elastic modulus of the rock mass is assumed herein to be unchanged. However, the load changes considering a stress gradient of $2.5 \mathrm{MPa} / 100 \mathrm{~m}$. The bulking coefficient varies at different levels. Hence, only the zero-subsidence range above the rib side is studied. The assignments are the same with those used in Figures 4 and 6, except for the VBS level and load. Figure 10 shows the influence of the level on the zerosubsidence range of the VBS. The zero-subsidence range increases as the VBS level becomes higher, thereby indicating that the sphere of influence grows in a high level. Moreover, the subsidence volume is almost ascertained.

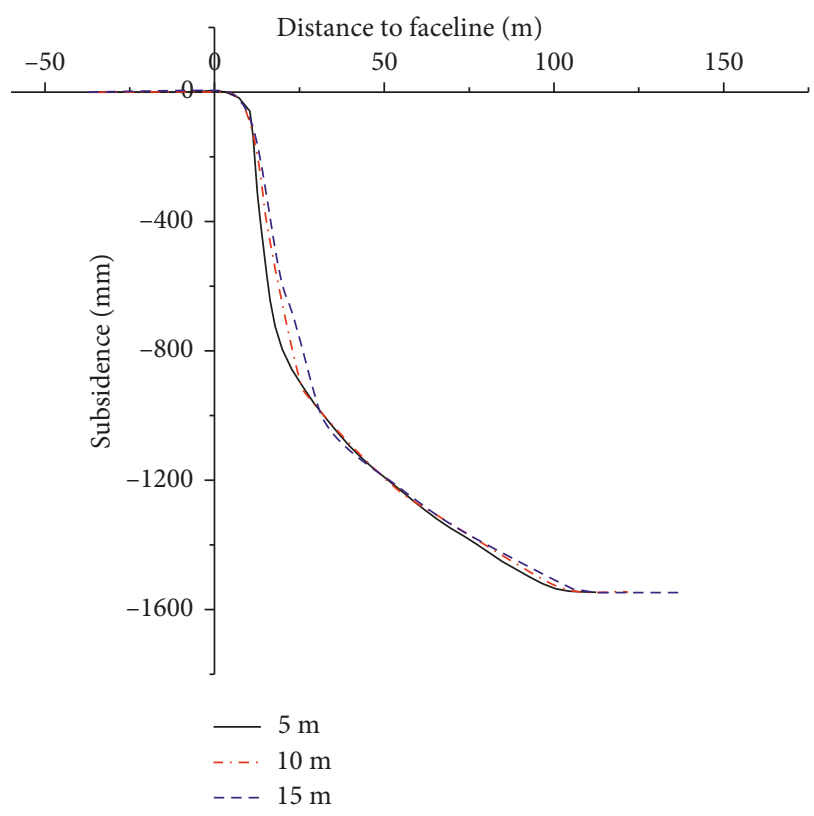

FIGURE 8: Influence of the block length on the subsidence of the voussoir beam structure.

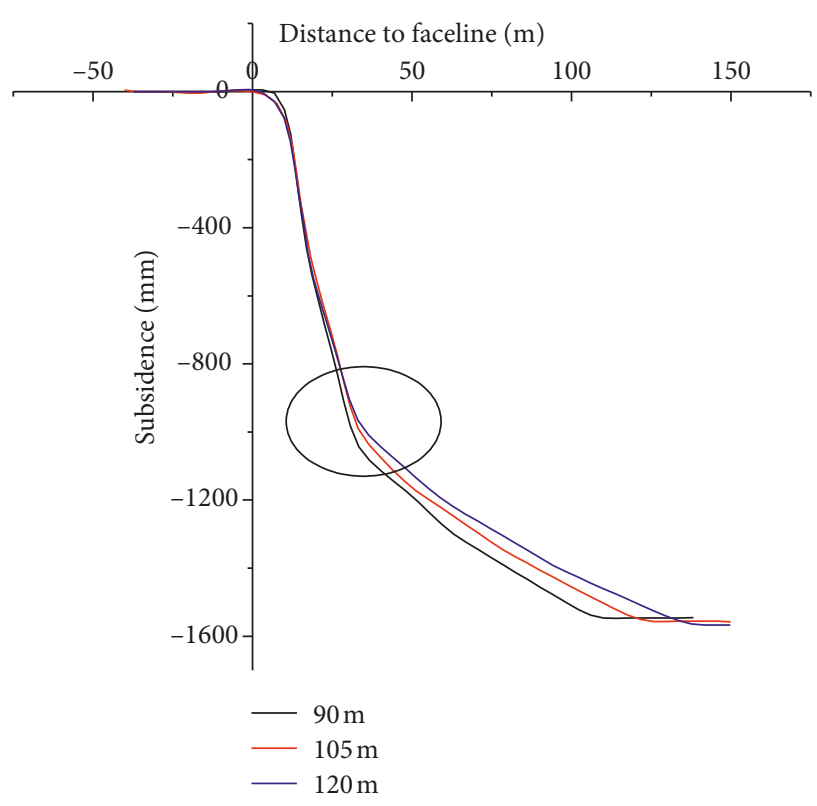

FIGURE 9: Influence of the width of the undercompacted zone on the subsidence of the voussoir beam structure.

Therefore, the subsidence curve becomes smoother in a higher level.

4.2.3. Influence of the Mining Height on the VBS Subsidence. The mining height is the main factor influencing the VBS subsidence. Figure 11 presents the influence of the mining height on the VBS subsidence in supercritical mining. The assignments are the same with those used in Figures 4 and 6, except for the mining height. Figure 11 


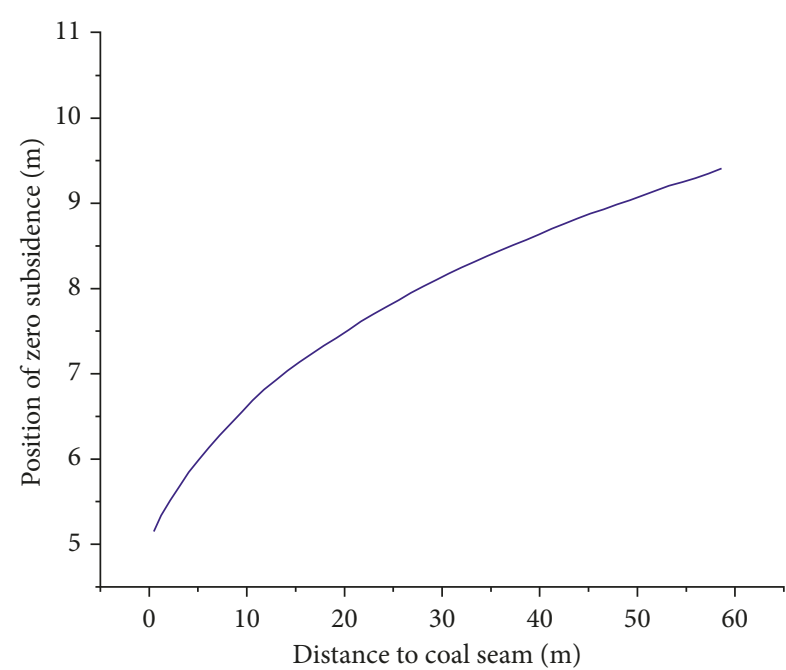

Figure 10: Influence of the level on the subsidence of the voussoir beam structure.

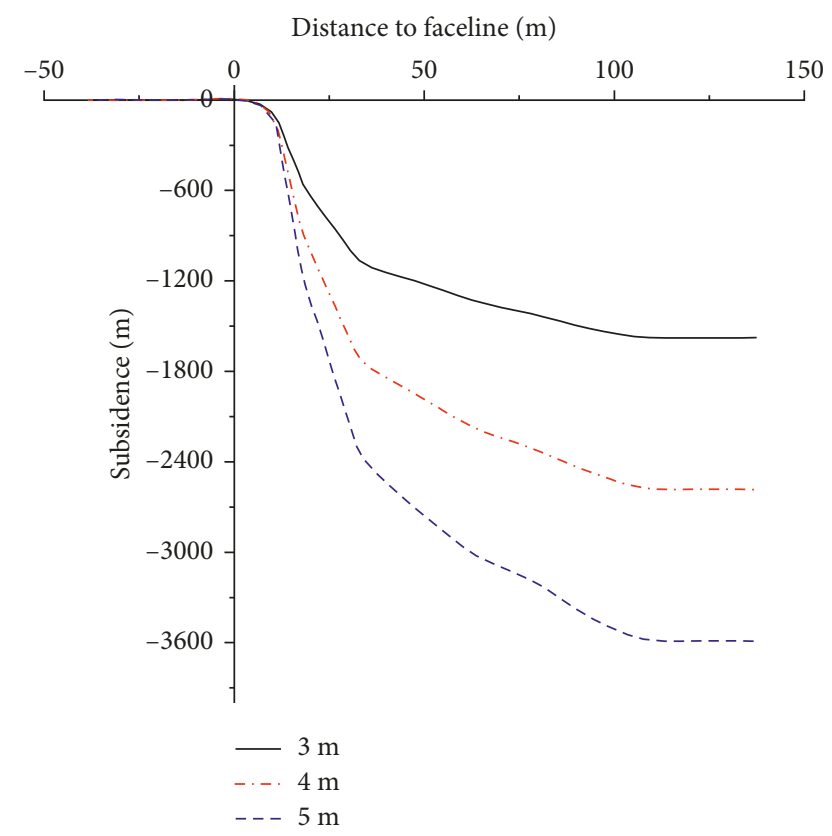

FIGURE 11: Influence of the mining height on the subsidence of the voussoir beam structure.

shows that the influence of the mining height on the subsidence above the rib side is negligible but significantly affects the VBS subsidence above the mined-out area. The subsidence increases, and the subsidence curve slope becomes steeper with the higher mining height.

4.3. Calculation Steps of the VBS Subsidence. The physical and mechanical parameters of the rock strata, including the elastic modulus, strata thickness, mining height, density, and tensile strength, and the mining subsidence parameters, including the angle of full subsidence, breaking angle, and bulking coefficient, are needed to calculate the VBS subsidence. The subsidence over the mined-out area and the rib side is then calculated accordingly. Finally, the maximum subsidence above the rib side should be added to each block subsidence above the mined-out area. Thus, the halfsubsidence curve of the VBS can be obtained. Figure 12 shows the detailed calculation steps. The subsidence parameters can be determined according to either the following methods or field measurements:

(1) The thickness of the overburden strata can be obtained through a geological histogram. The physical and mechanical parameters can be tested with in situ drilling cores in a laboratory. The values from the laboratory tests should be reduced because of the numerous geological structures in the field rock mass. The elastic modulus of the rock mass is approximately half that tested in the laboratory samples [24]. The block length can be calculated by theory of beams fixed at two sides.

(2) The angle of full subsidence determines the width of the undercompacted zone and the shear force magnitude. Moreover, it decides the number of blocks in the VBS. Whether the caved zone is compacted or not is related to the stress magnitude because stress determines the compaction degree. Only different levels of strata have the same width of compacted zone, and stress in the compacted zone of a level can be kept constant. Therefore, the width of the compacted zone in every level is fixed for one mining condition. Figure 13 shows the numerical width of the compacted zone in different levels (the subsidence magnitude is zoomed), where the width of the compacted zone in six different levels is almost the same. Hence, the angle of full subsidence can be obtained through field measurements.

(3) The angle between the horizontal line and the line connecting the coal rib to the rib near the fracture of each stratum is called the breaking angle. The relationship between the breaking angle and the ratio of compressive strength $\sigma_{\mathrm{s}}$ to tensile strength $\sigma_{\mathrm{t}}$ is expressed as follows [25]:

$$
\tan \varphi=\sqrt{\frac{\sigma_{\mathrm{s}}}{\sigma_{\mathrm{t}}}}
$$

(4) The maximum subsidence of the VBS is closely related to the KS breakage. The stress on the caved and fractured zones increases if the KS breaks. The rock mass compression then extends, and the bulking coefficient decreases. The bulking coefficient barely changes after a critical subsidence. The field measurements show that the bulking coefficient exponentially decreases upward from the coal seam $[26,27]$ and satisfies the following equation:

$$
k=a-b \ln \sum h,
$$




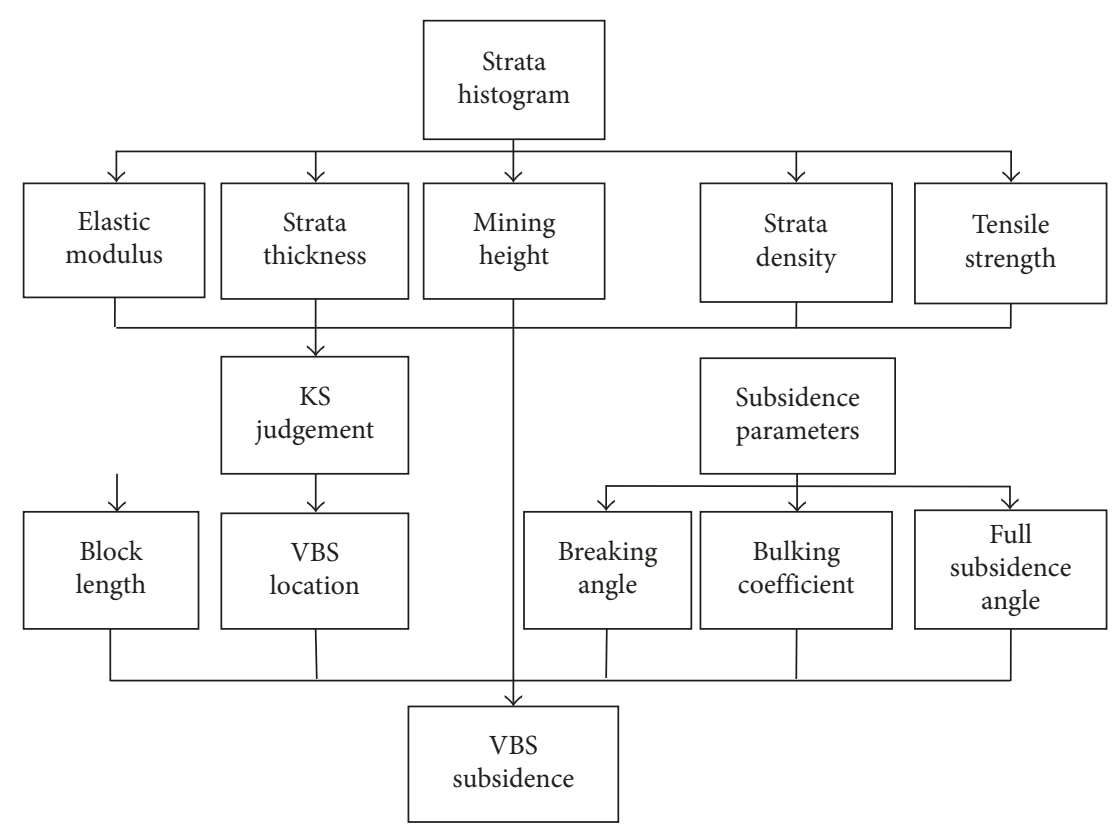

FIGURE 12: Subsidence calculation steps of the voussoir beam structure.

where $a$ and $b$ are the parameters related to geological conditions. The Yangquan Yi coal mine has $a$ and $b$ of 0.017 and 1.083, respectively, whereas the Kongzhuang coal mine has 0.037 and 1.151, respectively. $k$ is the bulking coefficient, and $\sum h$ is the height from the coal seam to the VBS.

\section{Case Study}

5.1. Case Study One. In the 1980s, overburden strata movement observations were conducted in some of the coal mines in China. One of these observations is referenced here to validate the subsidence model proposed in the present study [26]. The mining coal seam is Panel 8111 with a mining height of $1.8 \mathrm{~m}$ and a dip angle of $25^{\circ}-26^{\circ}$. The width and length of Panel 8111 are $112 \mathrm{~m}$ and $452 \mathrm{~m}$, respectively. The mining depth is $221 \mathrm{~m}$ with $153 \mathrm{~m}$ topsoil. The spacing of coal seams \#7 and \#8 is $24 \mathrm{~m}$. Figure 14 illustrates the observation boreholes drilled in the roadway of coal seam \#7.

The first VBS is a layer of sandstone with $4.6 \mathrm{~m}$ thickness and located $16.8 \mathrm{~m}$ away from the mining coal seam, which is the first layer of sandstone under coal seam \#7 presented in the dip cross section in Figure 14. The measured subsidence is represented with a dashed red line in Figure 15. The block length and the width of the undercompacted zone are $15 \mathrm{~m}$ and $90 \mathrm{~m}$, respectively. Therefore, seven blocks act in the VBS. The topsoil and bedrock densities are $1900 \mathrm{~kg} / \mathrm{m}^{3}$ and $2450 \mathrm{~kg} / \mathrm{m}^{3}$, respectively. Hence, the uniformly distributed stress on the compacted zone is $4.17 \mathrm{MPa}$ vertical to the coal seam. The shear force at the boundary of the first VBS above the rib side then becomes $187.7 \mathrm{MN} / \mathrm{m}$. They are assigned based on the literature as a result of the absence of a real elastic modulus [24]. The elastic moduli of the coal seam, voussoir beam, and rock mass between the coal seam and the voussoir beam are $3 \mathrm{GPa}, 8 \mathrm{GPa}$, and $5 \mathrm{GPa}$, respectively. The bulking coefficient is 1.051 according to (14). Consequently,

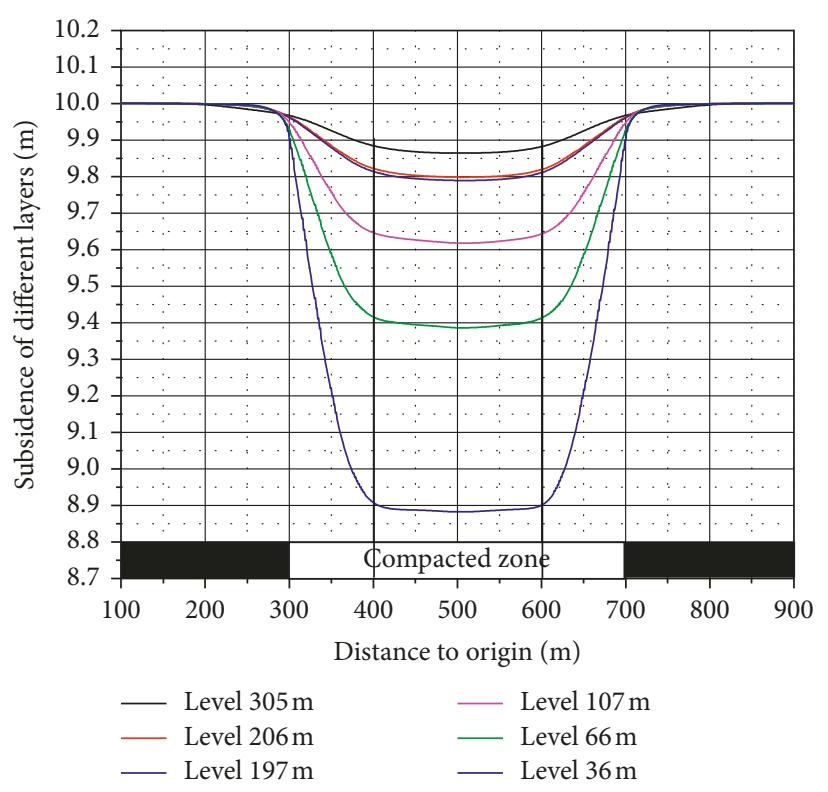

FIGURE 13: Width of the compacted zone of different levels in the numerical simulation.

the load to compression ratio is $79.5 \mathrm{MN} / \mathrm{m}^{3}$. The breaking angle is $59.2^{\circ}$ based on the measurements. The solid black line in Figure 15 depicts the theoretical subsidence of the VBS. The subsidence of the measurements and the theoretical calculations agrees well with each other.

5.2. Case Study Two. The subsidence of the upmost VBS can approximately represent the surface subsidence if the topsoil is extremely thin. The surface subsidence observed on Panel 31305 of the Wanli Yi coal mine of the Dongsheng colliery is borrowed here as the second example to verify the 


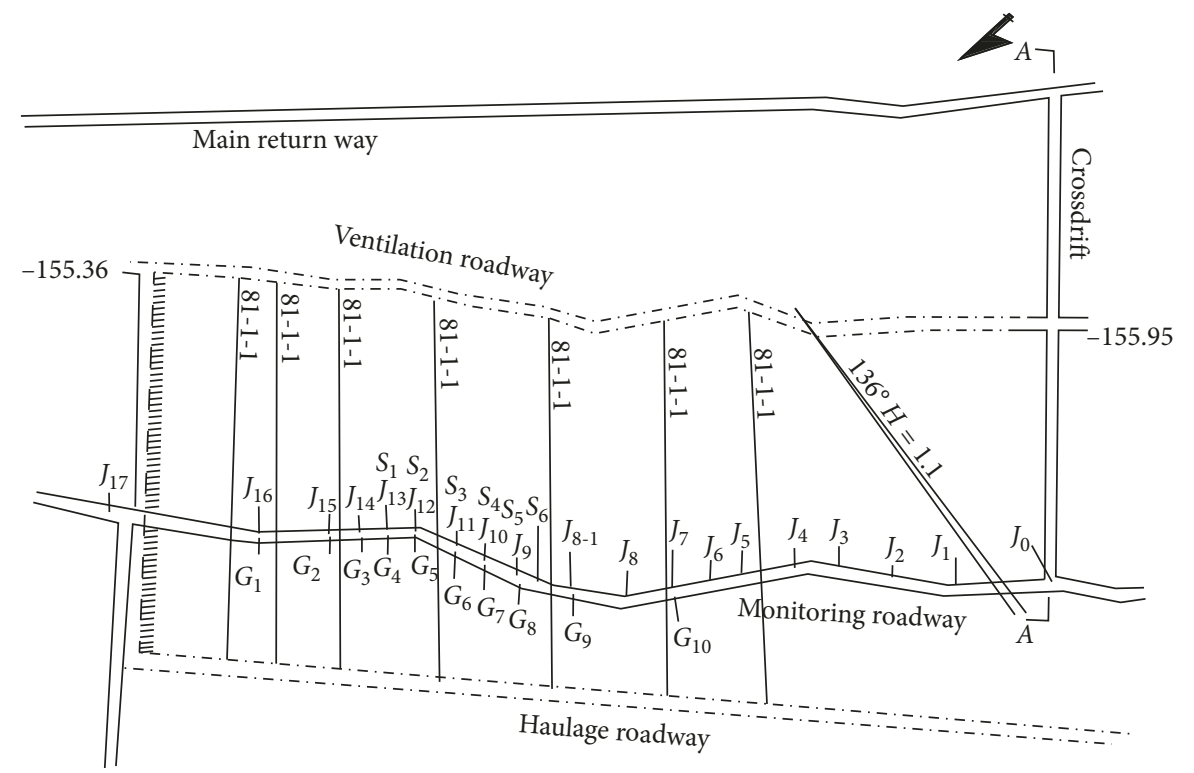

$J$-base point of level theodolite cross section

$G$-base point of survey

$S$-deep base point

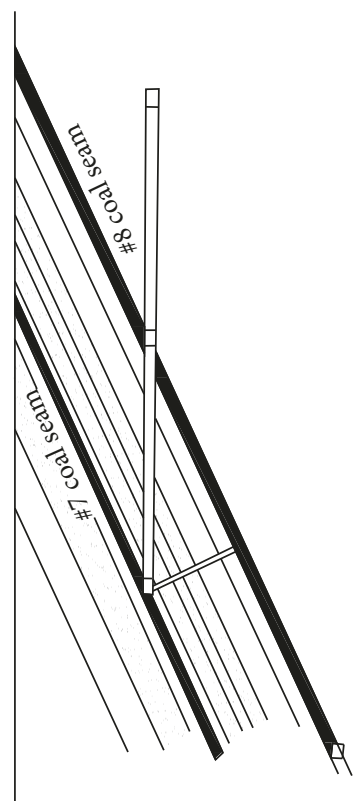

$A-A$ dip cross section

FIgURE 14: Arrangement of the rock movement observation boreholes (adaptation).

subsidence model [28]. The mining height is $4.9 \mathrm{~m}$, and the dip angle is $1.5^{\circ}-5^{\circ}$. The width and the length of Panel 31305 are $300 \mathrm{~m}$ and $2706 \mathrm{~m}$, respectively. The average mining depth is $145 \mathrm{~m}$ with $10 \mathrm{~m}$ topsoil (Table 1).

The block length and the undercompacted zone width are $50 \mathrm{~m}$ and $100 \mathrm{~m}$, respectively. Therefore, three blocks act in the VBS. The elastic modulus of the VBS and the rock mass under the VBS are $0.3 \mathrm{GPa}$ and $1 \mathrm{GPa}$, respectively. The overburden density is $2600 \mathrm{~kg} / \mathrm{m}^{3}$. Hence, the uniformly distributed stress is $2.34 \mathrm{MPa}$ on the PKS and is $4.42 \mathrm{MPa}$ on the lowest VBS. The shear force at the boundary of the first VBS above the rib side then becomes $221 \mathrm{MN} / \mathrm{m}$, while the bulking coefficient is 1.023 . Consequently, the load to compression ratio is $3.97 \mathrm{MN} / \mathrm{m}^{3}$, and the breaking angle is $90^{\circ}$ based on the measurements. The black line in Figure 16 denotes the theoretical subsidence of the VBS, while the red line is the measured surface subsidence. The subsidence of the measurements and the theoretical calculations agrees well with each other.

\section{Application Analysis of the VBS Formulae}

(1) The subsurface subsidence could have a significant influence on the performance of the gob well degasification system $[29,30]$, migration of groundwater [31, 32], and subsurface mine structures [33]. The KS theory shows that the subsidence of a KS can represent a set of strata displacements and the subsurface subsidence can be predicted by KS subsidence. Moreover, the VBS method is suitable for any VBS in the overburden. (This method is also applicable to dip coal seam by decomposing the gravity into the parallel and vertical directions to

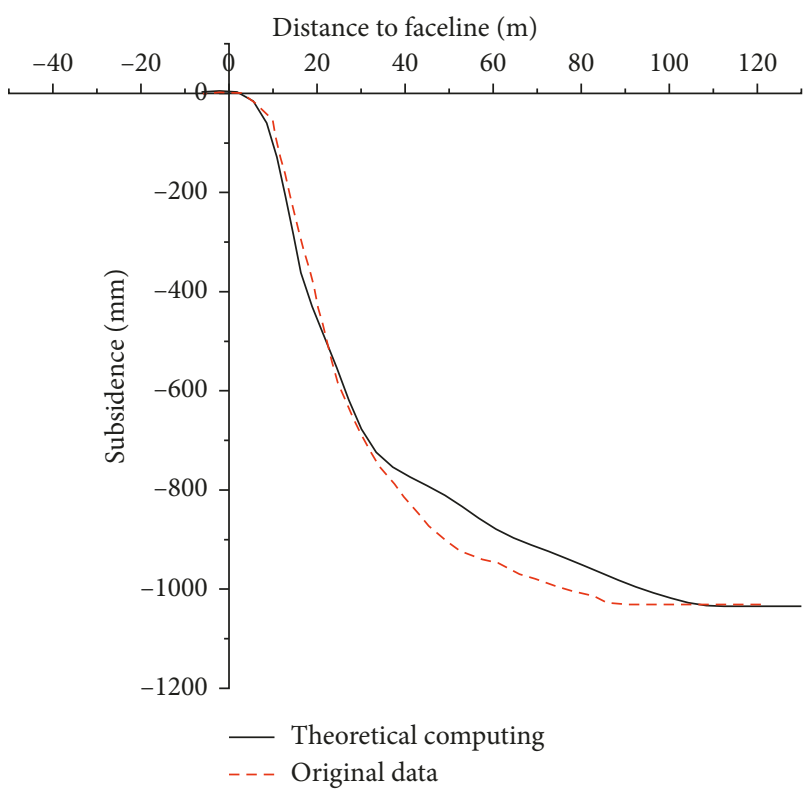

FIGURE 15: Subsidence of the field measurements and the theoretical calculations of the voussoir beam structure.

the coal seam. The subsidence of VBS is yet perpendicular to the coal seam). Therefore, the subsurface subsidence of any strata can be calculated with the subsidence calculation steps of VBS (Figure 12).

(2) The influence function method is one of the most commonly used methods for surface subsidence prediction in coal mines. Practices indicate that the overburden thick hard rock strata play an important 
TABle 1: Strata thickness and KS location.

\begin{tabular}{|c|c|c|c|c|}
\hline Thickness (m) & Depth (m) & Lithology & KS judgement & Limit span (m) \\
\hline 10 & 10 & Topsoil & & \\
\hline 20 & 30 & Medium-grained sandstone & & \\
\hline 60 & 90 & Sandy conglomerate & PKS & 50.001 \\
\hline 10 & 100 & Sandy mudstone & & \\
\hline 10 & 110 & Coarse-grained sandstone & & \\
\hline 10 & 120 & Fine-grained sandstone & & \\
\hline 10 & 130 & Medium-grained sandstone & & \\
\hline 15 & 145 & Coarse-grained sandstone & & 23.341 \\
\hline 10 & 155 & Fine-grained sandstone & SKS & 40 \\
\hline 5 & 160 & Mudstone & & \\
\hline 10 & 170 & Fine-grained sandstone & SKS & 16.976 \\
\hline 5 & 175 & Siltstone & & \\
\hline 4.9 & 179.9 & Coal seam & & \\
\hline
\end{tabular}

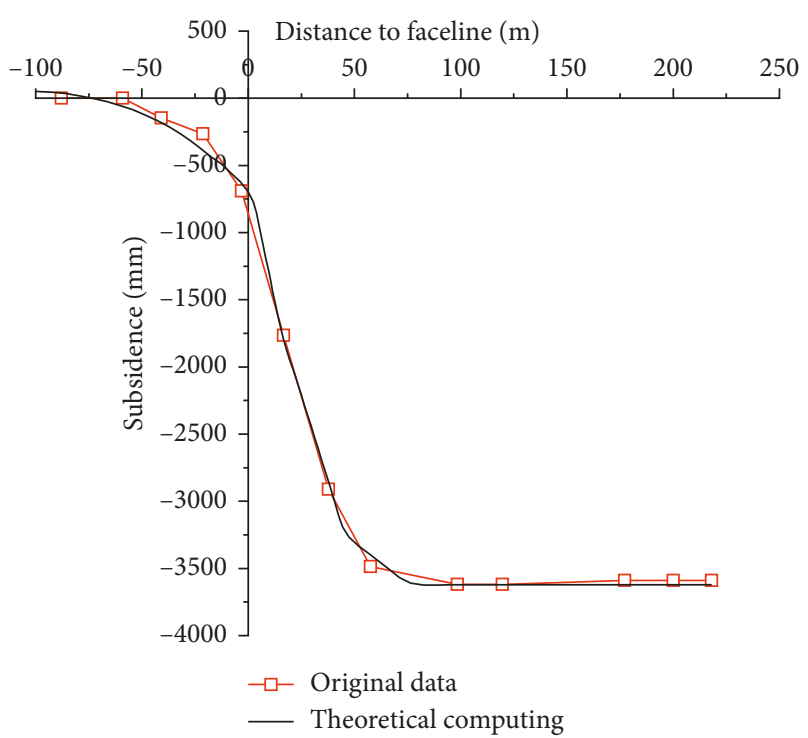

Figure 16: Subsidence of the surface measurements and the theoretical calculations.

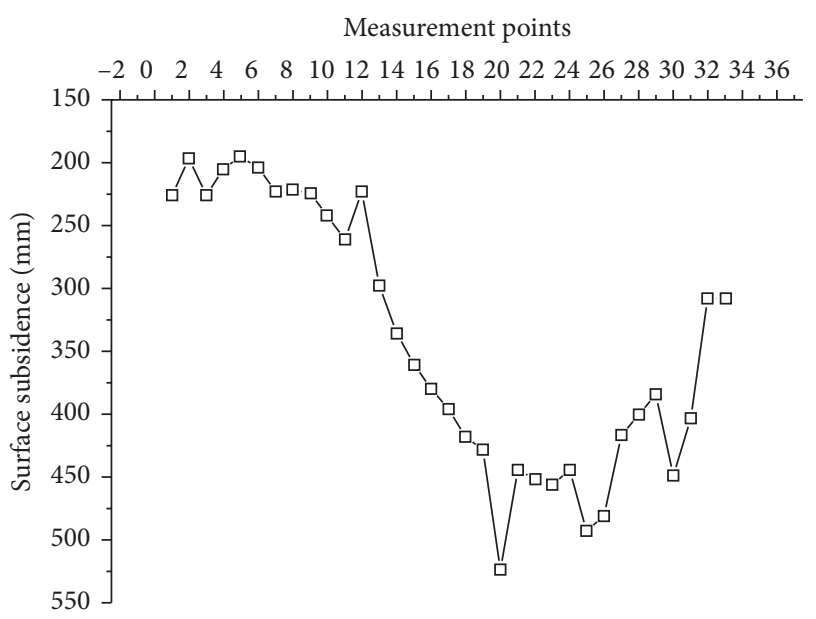

FIGURE 17: The subsidence curve of the strike of Haizi II 1024 face after mining II 1022 face. role on the surface subsidence. The surface subsidence coefficient is relatively large in the Huaibei mining area of China in which the surface subsidence coefficient of critical mining can be as high as one. In the Haizi coal mine of the Huaibei mining area, there is a thick hard layer in the overburden rock mass. The depth of 600 meters and the width and advancing length of the II 1022 and II 1024 longwall working face reaches $390 \mathrm{~m}$ and $560 \mathrm{~m}$, respectively. There should be a $2.0-2.5 \mathrm{~m}$ surface subsidence according to "Coal Mining Regulations and Coal Pillar Design Affected by Buildings, Water Bodies, Railways and Main Roadways" of China. However, the measured maximum surface subsidence is only $0.526 \mathrm{~m}$ (Figure 17). This result illustrates that the influence function method has errors in the surface subsidence prediction when there is a typical thick and hard stratum. Nevertheless, the advantage of the VBS method is based on the physical and mechanical parameters of the overburdens, not on the empirical data. The surface subsidence is equivalent to the top VBS subsidence when the topsoil is thin enough because the topsoil and the top KS can be treated as a set of stratum. The surface subsidence can be theoretically calculated according to the deformation characteristics of the topsoil if it is thick [34]. In short, the subsidence method of the VBS is a good complement and extension for the existing prediction methods of the surface subsidence.

\section{Conclusions}

It is quite important to study the subsidence of overburden and surface caused by coal mining in that water inrush and environmental damage result from the subsidence of the overburden and surface. Although many methods were proposed to predict surface subsidence, most of these methods did not consider the effect of key strata. However, field investigations and laboratory experiments indicated 
that the key strata control the surface subsidence. When the key strata break, it control the surface with a voussoir beam structure formed. The subsidence of the voussoir beam occurs above both the mined-out and rib-side area. At present, only the displacement of blocks above the minedout area was studied, and the subsidence line was not an S-shaped curve, which was in contradiction with the field investigations. In addition, the previous calculation formula of blocks displacement was revised and improved in this paper. In a word, the following conclusions are obtained from this study:

(1) The overlying VBS is divided into two parts: one above the mined-out area and another above the rib sides. The breaking blocks above the mined-out area interlock with each other, forming a stable mechanical structure. Its subsidence can be obtained by structure mechanics. Meanwhile, the VBS above the rib sides deforms like a complete beam, and its subsidence can be derived by continuum mechanics. Adding the maximum subsidence of the VBS above the rib side to each block subsidence of the VBS above the mined-out area and combining these two subsidence parts result to the half-subsidence curve of the VBS, which is an S-shaped curve. The theoretical subsidence of the VBS agrees well with the field measurements.

(2) The undercompacted zone width, and not the block length, determines the S-shaped subsidence curve. The zero-subsidence range increases as the VBS level becomes higher. The subsidence increases, and the subsidence curve slope becomes steeper with the higher mining height.

(3) The proposed subsidence model is suitable to any VBS layer. The VBS subsidence can approximate the surface subsidence when the topsoil is extremely thin but cannot represent the surface subsidence when the topsoil is thick because the topsoil has its own complex movement law. Therefore, only the VBS subsidence is studied herein. The overburden subsidence-based surface subsidence prediction method will be studied next.

\section{Conflicts of Interest}

The authors declare that they have no conflicts of interest.

\section{Authors' Contributions}

Changchun He performed the technological development, prepared and edited the manuscript, and performed the program design; Jialin Xu revised and reviewed the manuscript. Guozhong Hu proofread the manuscript.

\section{Acknowledgments}

This work was supported by the Fundamental Research Funds for the Central Universities (Grant no. 2015XKZD04) and a Project Funded by the Priority Academic Program
Development of Jiangsu Higher Education Institutions (Grant no. SZBF2011-6-B35).

\section{References}

[1] V. Palchik, "Formation of fractured zones in overburden due to longwall mining," Environmental Geology, vol. 44, no. 1, pp. 28-38, 2003.

[2] G. Z. Hu, N. Yang, G. Xu, and J. L. Xu, "Experimental investigation on variation of physical properties of coal samples subjected to microwave irradiation," Journal of Applied Geophysics, vol. 150, pp. 118-125, 2018.

[3] Z. Q. Hu, F. Hu, J. Li, and H. Li, "Impact of coal mining subsidence on farmland in eastern China," International Journal of Surface Mining Reclamation and Environment, vol. 11, no. 2, pp. 91-94, 1997.

[4] R. K. Tiwary, "Environmental impact of coal mining on water regime and its management," Water, Air, and Soil Pollution, vol. 132, no. 1-2, pp. 185-199, 2001.

[5] I. A. Wright, B. McCarthy, N. Belmer, and P. Price, "Subsidence from an underground coal mine and mine wastewater discharge causing water pollution and degradation of aquatic ecosystems," Water, Air, and Soil Pollution, vol. 226, no. 10, p. 348, 2015.

[6] O. Arkoc, S. Ucar, and C. Ozcan, "Assessment of impact of coal mining on ground and surface waters in Tozaklı coal field, Kirklareli, northeast of Thrace, Turkey," Environmental Earth Sciences, vol. 75, no. 6, p. 514, 2016.

[7] E. F. Salmi, M. Nazem, and M. Karakus, "Numerical analysis of a large landslide induced by coal mining subsidence," Engineering Geology, vol. 217, pp. 141-152, 2017.

[8] A. Asadi, K. Shahriar, K. Goshtasbi, and K. Najm, "Development of a new mathematical model for prediction of surface subsidence due to inclined coal-seam mining," Journal of the South African Institute of Mining and Metallurgy, vol. 105, no. 1, pp. 15-20, 2005.

[9] B. Ghabraie, G. Ren, X. Zhang, and J. Smith, "Physical modelling of subsidence from sequential extraction of partially overlapping longwall panels and study of substrata movement characteristics," International Journal of Coal Geology, vol. 140, pp. 71-83, 2015.

[10] P. R. Sheorey, J. P. Loui, K. B. Singh, and S. K. Singh, "Ground subsidence observations and a modified influence function method for complete subsidence prediction," International Journal of Rock Mechanics and Mining Sciences, vol. 37, no. 5, pp. 801-818, 2000.

[11] X. Cui, X. X. Miao, and J. Wang, "Improved prediction of differential subsidence caused by underground mining," International Journal of Rock Mechanics and Mining Sciences, vol. 37, no. 4, pp. 615-627, 2000.

[12] S. J. Chen, H. L. Wang, H. Y. Wang, W. J. Guo, and X. S. Li, "Strip coal pillar design based on estimated surface subsidence in Eastern China," Rock Mechanics and Rock Engineering, vol. 49, no. 9, pp. 1-10, 2016.

[13] J. L. Xu and M. G. Qian, "Study on the influence of key strata movement on subsidence," Journal of China Coal Society, vol. 25, pp. 122-126, 2000.

[14] J. L. Xu, M. G. Qian, and W. B. Zhu, "Study on influences of primary key stratum on surface dynamic subsidence," Chinese Journal of Rock Mechanics and Engineering, vol. 24, no. 5, pp. 787-791, 2005.

[15] W. B. Zhu, J. L. Xu, and X. S. Shi, "Research on influence of overburden primary key stratum movement on surface subsidence with in-situ drilling test," Chinese Journal of Rock Mechanics and Engineering, vol. 28, no. 2, pp. 403-409, 2009. 
[16] S. S. Peng, Coal Mine Ground Control, China University of Mining and Technology Press, Xuzhou, China, 3rd edition, 2013.

[17] A. I. Sofianos, "Analysis and design of an underground hard rock voussoir beam roof," International Journal of Rock Mechanics and Mining Sciences, vol. 33, no. 2, pp. 153-166, 1996.

[18] M. Tsesarsky, "Deformation mechanisms and stability analysis of undermined sedimentary rocks in the shallow subsurface," Engineering Geology, vol. 133-134, no. 4, pp. 16-29, 2012.

[19] Y. Luo and B. Qiu, "Enhanced subsurface subsidence prediction model that considers overburden stratification," International Journal of Mining Engineering, vol. 64, no. 10, pp. 78-84, 2012.

[20] M. G. Qian, S. P. Wu, and J. L. Xu, Control of Mine Ground Pressure and Strata, China University of Mining and Technology Press, Xuzhou, China, 2nd edition, 2010.

[21] M. Bai, T. Q. Liu, and W. L. Zhong, "The study of strata and surface movement by using the method of mechanics," Journal of China Coal Society, vol. 3, pp. 27-38, 1982.

[22] C. D. Su, M. Gu, X. Tang, and W. B. Guo, "Experiment study of compaction characteristics of crushed stones from coal seam roof," Chinese Journal of Rock Mechanics and Engineering, vol. 31, no. 1, pp. 18-26, 2012.

[23] K. Morsy and S. S. Peng, "Numerical modeling of the gob loading mechanism in longwall coal mines," in Proceedings of the 21st International Conference on Ground Control in Mining, pp. 58-67, Morgantown, WV, USA, August 2002.

[24] H. Yavuz, "An estimation method for cover pressure reestablishment distance and pressure distribution in the goaf of longwall coal mines," International Journal of Rock Mechanics and Mining Sciences, vol. 41, no. 2, pp. 193-205, 2004.

[25] Y. S. Li, J. Z. Wang, and Y. Cheng, "An analysis on subsidence factors in mining subsidence area," Mining Research and Development, vol. 2, pp. 4-6, 1998.

[26] H. C. Li and M. G. Qian, "A study of ascending mining method at Kongzhuang mine," Journal of China University of Mining and Technology, vol. 2, pp. 11-23, 1982.

[27] G. L. Guo, X. X. Miao, and Z. N. Zhang, "Research on ruptured rock mass deformation characteristics of longwall goafs," Science Technology and Engineering, vol. 2, pp. 44-47, 2002.

[28] B. L. Wei, "Study on strata movement and subsidence of Shenfu coal mine," Dissertation, Changchun University of Science and Technology, Changchun, China, 1999.

[29] C. Ö. Karacan, "Reconciling longwall gob gas reservoirs and venthole production performances using multiple rate drawdown well test analysis," International Journal of Coal Geology, vol. 80, no. 3, pp. 181-195, 2009.

[30] F. Wang, C. Zhang, and N. Liang, "Gas permeability evolution mechanism and comprehensive gas drainage technology for thin coal seam mining," Energies, vol. 10, no. 9, pp. 1382-1399, 2017.

[31] Y. Zhang, S. Cao, L. Lan, and H. Yan, "Analysis of development pattern of a water-flowing fissure zone in shortwall block mining," Energies, vol. 10, no. 6, pp. 734-146, 2017.

[32] C. J. Booth, "Groundwater as an environmental constraint of longwall coal mining," Environmental Geology, vol. 49, no. 6, pp. 796-803, 2006.

[33] Y. Huang, J. Zhang, W. Yin, and Q. Sun, "Analysis of overlying strata movement and behaviors in caving and solid backfilling mixed coal mining," Energies, vol. 10, no. 7, pp. 1057-1072, 2017.

[34] D. M. Shu and A. K. Bhattacharyya, "Relationship between sub-surface and surface subsidence-a theoretical model," Mining Science and Technology, vol. 11, no. 3, pp. 307-319, 1990. 


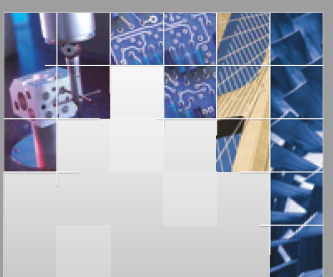

\section{Enfincering}
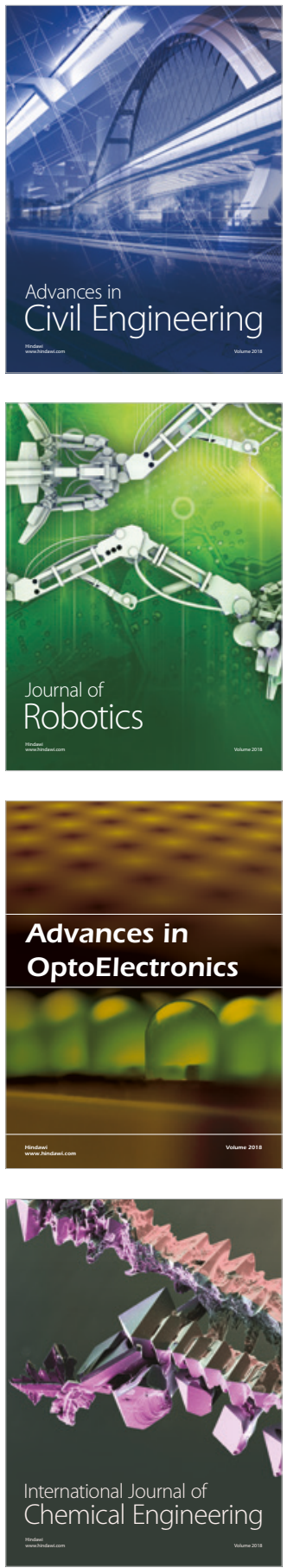

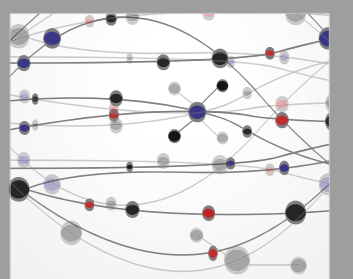

\section{Rotating \\ Machinery}

The Scientific World Journal

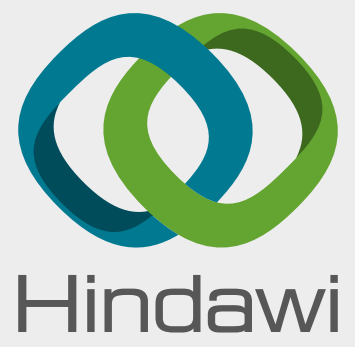

Submit your manuscripts at

www.hindawi.com
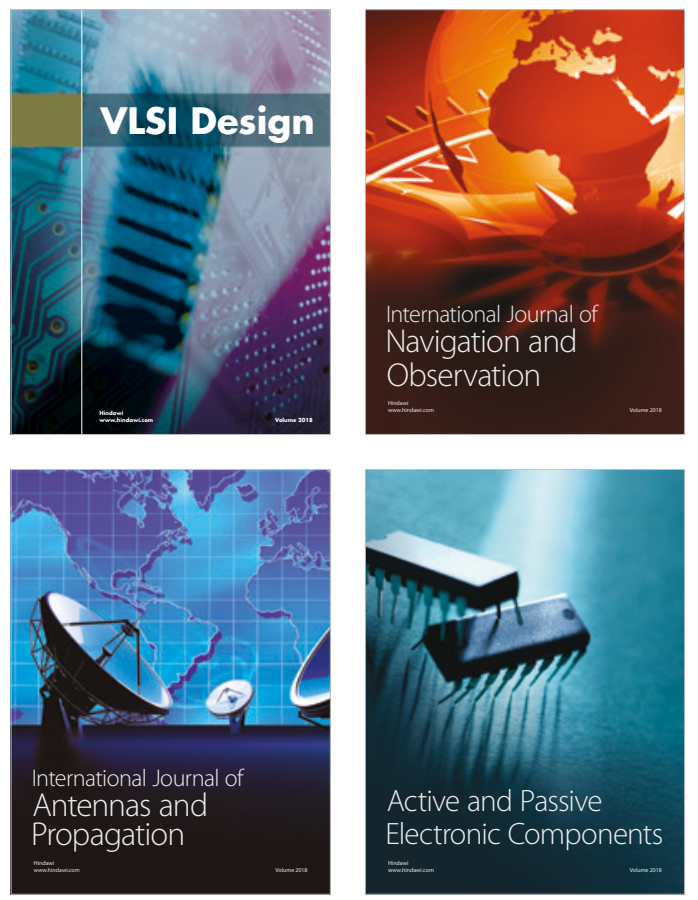
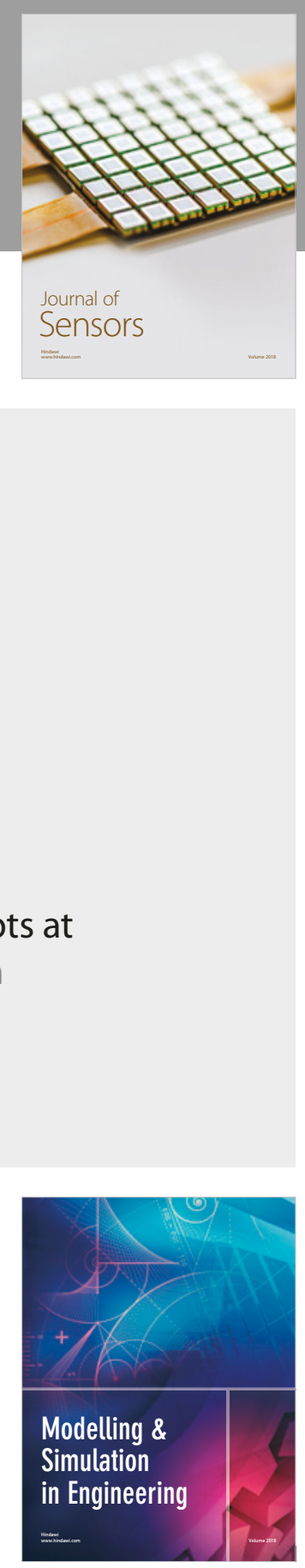

\section{Advances \\ Multimedia}
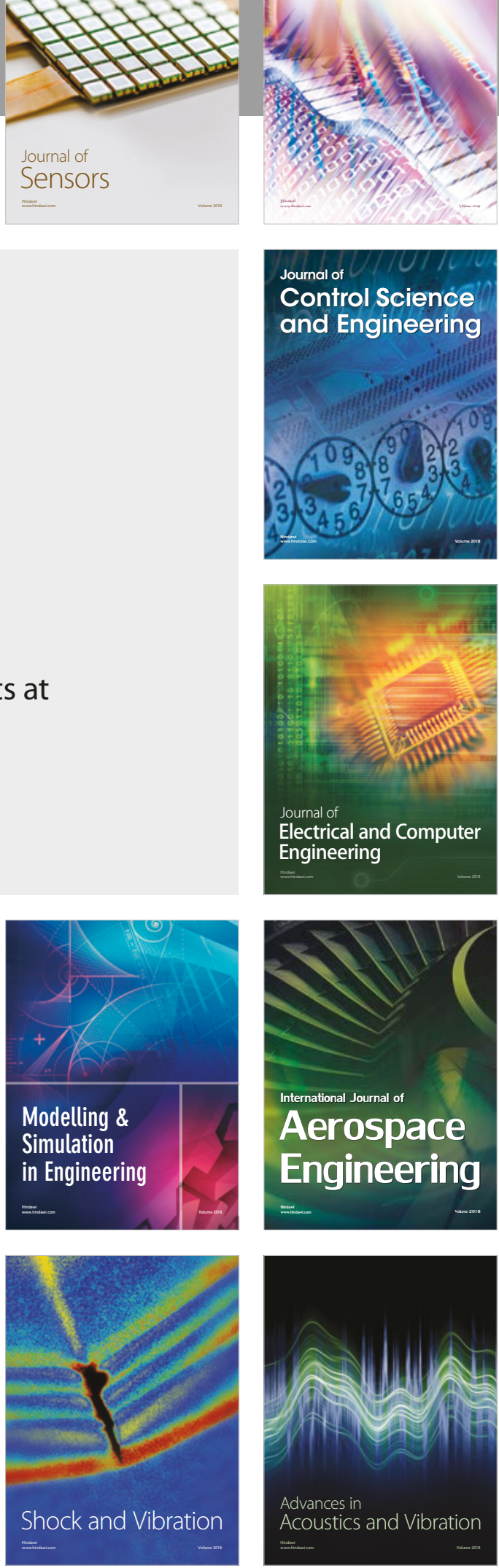